\title{
VALENCIA EN EL PACTO DE TUDMIR
}

\author{
Por \\ MARIA JESÚS RUBIERA MATA
}

En los tres textos árabes del pacto de Tudmir: Al- ${ }^{c} U d r i ̄(1)$, al-Dabbi (2) y al-Himyari, aparece Blint/ah como uno de los nombres de las siete ciudades sometidas por capitulación a ${ }^{c} \mathrm{Abd}$ al- ${ }^{c} \mathrm{Aziz}$ ibn Mūsā en el año $713(94 \mathrm{H})$. Sobre la identificación de este lugar ha habido teorias de todos los gustos, la mayor parte de las cuales tranforman el texto consonántico, alterando los puntos diacríticos, hecho que sí podía admitirse cuando sólo se conocía este texto a partir de la versión de al-Dabbi, como en época de Gaspar Remiro (4), pero que resulta difícilmente sostenible ante los tres textos ya citados (5).

$F$. Simonet identificó B/ntlah con Valencia, teoría que sigue en la actualidad J. Vallvé (6). Esta teoría se basa en que en la versión del pacto de Tudmir que aparece en la Crónica del moro Rasis (7), cuya coincidencia con los textos árabes del mismo la muestran como procedente del Ajbär mulük de al-Rāzi y no como una interpolación, aparecen como las ciudades sometidas "por pleitesian a ${ }^{\circ} \mathrm{Abd}$ al- ${ }^{\mathrm{C}} \mathrm{Az} \bar{z} \mathrm{z}$, Orihuela, Lorca, Alicante y Valencia. Las tres primeras aparecen también, sin ninguna duda, en los textos árabes, y podría pensarse, en efecto, que la cuarta ciudad fuese Bintlah, cuyas primeras consonantes coinciden con la transcripción de Valentia. La terminación anómala la explica el profesor Vallvé como una transcripción de sedes valentina, ingeniosa hipótesis que en nuestra opinión tiene el inconveniente de tener que transformar el texto consonántico.

Sin tener que realizar esta operación, creemos que esta identificación pue-

(1) Tarsic al-ajabâar. Edo. por Abd al-Aziz al-Ahwani, Madrid, 1965, pp. 4 y 5.

(2) Bugyat al-Multamis, ed. Codera-Ribera. B, A. H. III, Madrid, 1885, p. 259.

(3) E. Lévi-Provençal, La Péninsule lbérique au Moven Âge d'aprés le Kitab ar-Rawd al-Mítar fi habar al-aqtar' d'ibn 'Abd al-Mun'im al-Himyari, Leyden, 1938, pp. 62 y 79; Kitab al-Rawd al MF́tar $f$ jabar al-Aqtar de atHimyari, ed. 1. "Abbas, Beirut, 1975, pp. 131-132.

(4) Historia de Murcia Musulmana, Zaragoza, 1905. Reedición, Murcia, 1980, pp. 11-27.

(5) Teoria seguida por M. Sánchez Guarner, Histdria del Pais Valencia. 1. Epoca musulmana, Barcelona, 1965 , pp. 201-202: P. Guichard, "Le peuplement de la région de Valence aux deux premièrs siécles de la domination musulmane». Mélanges de la Casa de Velázquez, V, 1969, pp. 103-58.

(6) Historia de los mozárabes, Madrid, 1897-1903, pp. 56 y 799. Citado por J. Vallvé, "La cora de Tudmir, AlAndalus, XXXVII, 1972, p. 148.

(7) Edicióra de Diego Catalán y Marfa Soledad de Andrés, Madrid, o. 359. 
de ser válida con una diferente vocalización de la que se ha dado como Balantalah. Cabría pensar que esta palabra tendría el sufijo átono del diminutivo ula, tan frecuente en el latín vulgar hispánico, es decir Balentula: R. Menéndez Pidai estudió el fenómeno en diversos topónimos hispánicos: Piedrola (Ciudad Real), Petrola (Albacete) frente a numerosos Piedra o Petra; Espuéndolas (Huesca), frente a spuenda, y desde luego el ejemplo más significa tivo Toletola, Toledola, en árabe Tulaytula, nombre vulgar de Toledo (8).

Si la capital del reino godo era conocida como Tolètula en el siglo VIII, Valentia, mucho menos importante en esta época, bien podía ser conocida con la misma sufijación afectiva. La única diferencia es que Toledo hubo de esperar a la reconquista para recobrar su nombre culto y Valentula lo recuperó enseguida según muestra la transcripción árabe de Balansiyya.

La vinculación de Valencia a Tudmir ya fue hecha notar por F. Simonet a través de la denominación de Valencia de Tudmír en un códice mozárabe de 1049 (9). El profesor Vallvé añade la vinculación de Valencia a la Provincia Eartaginense (10).

A esta vinculación se une un dato que ha pasado hasta ahora inadvertido: en el Muqtabis de Ibn Hayyan referido al califa al-Hakam II (11) se mencionan los pund sirios de al-Andalus y se dice: "el ŷund de Egipto, que son la gente de Tudmir y Valencia». Es muy conocido que el $\hat{Y} u n d$ de Egipto se instaló en Tudmir, con lo que esta región (12) se convirtió en cora muŷannada, pero no ha" bía ninguna referencia a su instalación en Valencia. La única explicación plausible es que en el siglo VIII Valencia perteneciese a Tudmïr y los historiadores no necesitasen explicitar que se había instalado en ella, ya que estaba comprendida en la zona de Tudmir.

La presencia de Valencia en el pacto de Tudmir refuerza nuestra hipótesis, expuesta en otro lugar, de la relación de las ciudades que entran en el mismo, con la gran calzada romana llamada Vía Augusta, ya que Valencia era una de las mansiones de su itinerario (13).

(8) "Sufijos átonos" en Toponimia prerrománica hispana, Madrid, 1968, pp. 61-70.

(9) Vallvé, op. cit., ibidem.

(10) lbidem.

(11) Anales palatinos del Califa de Córdoba Al-Hakam III, por 'Isa ibn Ahmad Al Razi, traducción de Emilio Garcia Gómez, Madrid, 1967, p. 242.

(12) Al-CUdrí, op. cit., p. 1.

(13) Villena en las calzadas romana y árabe, Alicante, 1985 